\title{
Vegetation - soils relationships in a wetland area of the Orinoco delta plain (Venezuela)
}

\author{
T. Vegas-Vilarrúbia ${ }^{1}$, P. López ${ }^{1}$, F. Baritto ${ }^{2}$, G. Meleán ${ }^{2}$, \\ M. E. Ponce ${ }^{2} \&$ O. Gómez ${ }^{2}$ \\ ${ }^{I}$ Department of Ecology, Barcelona University, Spain \\ ${ }^{2}$ Geohidra Consultores C.A., Caracas, Venezuela
}

\begin{abstract}
The Orinoco Delta is one of the world's last great river deltas with pristine ecosystems. But it is also an important oil and gas reservoir area. Currently, little scientific and factual knowledge is available to assess the effect of oil exploitation activities. Understanding vegetation and soils relationships is fundamental to delineate conservation strategies to maintain species richness, essential ecological processes and life support systems. To meet these needs, our research objectives were to characterize soil conditions supporting different vegetation units of the Lower Orinoco Plain and to relate soil characteristics with vegetation assemblages. For these purposes, surface and bottom soil samples were taken in 227 sites, which were distributed proportionally to each vegetation unit coverage. Samples were analysed for salinity, chlorides, carbonates, $\mathrm{pH}$, organic carbon, exchangeable acidity, aluminium, hydrogen, calcium, potassium and sodium. Average thickness of the surface organic layer was $2.32 \mathrm{~m}$, reaching $6 \mathrm{~m}$ in some places. Organic carbon content did not differ significantly among soils from different vegetation units. Lowest surface $\mathrm{pH}$ values were found in forests and meadows $(<4.5)$. Bottom $\mathrm{pH}$ was less variable and almost neutral. The highest salinity values were found in mangrove soils $(1.80 \% \pm 0.12)$, the lowest in palm forests $(0.06 \% \pm 0.02)$. Main differences among soil samples were related with cation exchange capacity $(68.3 \mathrm{meq} / 100 \mathrm{~g} \pm 81.5)$, percent base saturation $(91.9 \% \pm 11.0)$, and acidity $(2.30 \mathrm{meq} / 100 \mathrm{~g} \pm 3.46)$. Our results indicated that content of salts and cations and soil acidification were the main factors in determining vegetation arrangements.
\end{abstract}

Keywords: soil acidity, organic matter, salinity, cation exchange capacity, mangroves, swamp forests, meadows. 


\section{Introduction}

One of the main objectives of activities devoted to Nature conservation purposes is to assure survival in the long term of the largest possible number of species. Nowadays, the rate of habitat loss is very high and points out the necessity of obtaining information about species location, specific composition of natural communities and, in particular, about those areas possessing high biodiversity, in order to promote conservation. Venezuela has been qualified as one of the six South American countries possessing "megadiversity", [16]. The Orinoco Delta region largely contributes to this perception, being a landscape of considerable biogeographic significance that concentrates a huge number of species. In the late nineties, different multinational initiatives came together to take over the crude oil on- and offshore prospecting of the Orinoco Delta, in the frame of the Venezuelan oil industry openness of 1995 [3]. Though, little scientific and factual knowledge was available to evaluate to which extent the purposed oil exploration projects could affect the associated wetland environment. The impact of the oil industry on deltaic and coastal environments has been largely documented worldwide $[1,10]$. A general agreement exists upon the urgent need to combine a holistic approach to assess environmental risk [9] with site and purpose-specific knowledge and regulations [15], in order to provide efficient environmental protection. More scientific research is required to adjust the existing national environmental regulations and to choose appropriate techniques to minimize environmental impacts resulting from exploration activities. The present study is based on vegetation and soil data contained in the Base Line Study of the Punta Pescador area [5] situated in the Lower Orinoco Delta region. Understanding vegetation and soils relationships is fundamental to delineate conservation strategies to maintain species richness, essential ecological processes and life support systems. To meet these needs, our research objectives were 1) to characterize soil conditions supporting different vegetation units of the Lower Orinoco Plain; 2) to group soils according to variables of ecological importance; 3) to relate soil assemblages with vegetation units; 4) to assess the ecosystem's vulnerability based on soil-vegetation relationships.

\section{Study site}

The Orinoco Delta $\left(42,000 \mathrm{~km}^{2}\right)$ is a huge wetland system formed by a fluviomarine sedimentary plain crossed by numerous distributaries and tidal channels. Tectonic processes and the effect of fluvial inputs and marine currents have given raise to distinct landscapes: a) the Upper Delta with the predominance of fluvial sedimentation; b) the Middle Delta dominated by swampy fluvio-marine plains; c) the Lower Delta, embracing the most extended part in contact with the sea. The prevailing climate type is moist tropical with precipitations surpassing $1.800 \mathrm{~mm}$ year $^{-1}$. Peat/ mud and silt/sand substrate alternate in this landscape, and hydromorphic entisol and histosols whith bad drainage, acidic $\mathrm{pH}$, and low base exchange capacity are common [14]. The study area is located in the lower Orinoco delta plain, fig. 1. It covers $941.9 \mathrm{~km}^{2}$ and includes an extended portion 
in contact with the Atlantic Ocean. Geomorphology, hydrology, and ecology are governed by semi-diurnal tides ranging $2.6 \mathrm{~m}$ variation in average. Tidal channels have brackish waters with salinities between $0.1-31.4 \%$ on and neutral to acidic $\mathrm{pH}$ values. Clays and silts prevail $(>80 \%)$, the soil organic matter content is between 30 and $40 \%$ and natural moisture $>80 \%$.

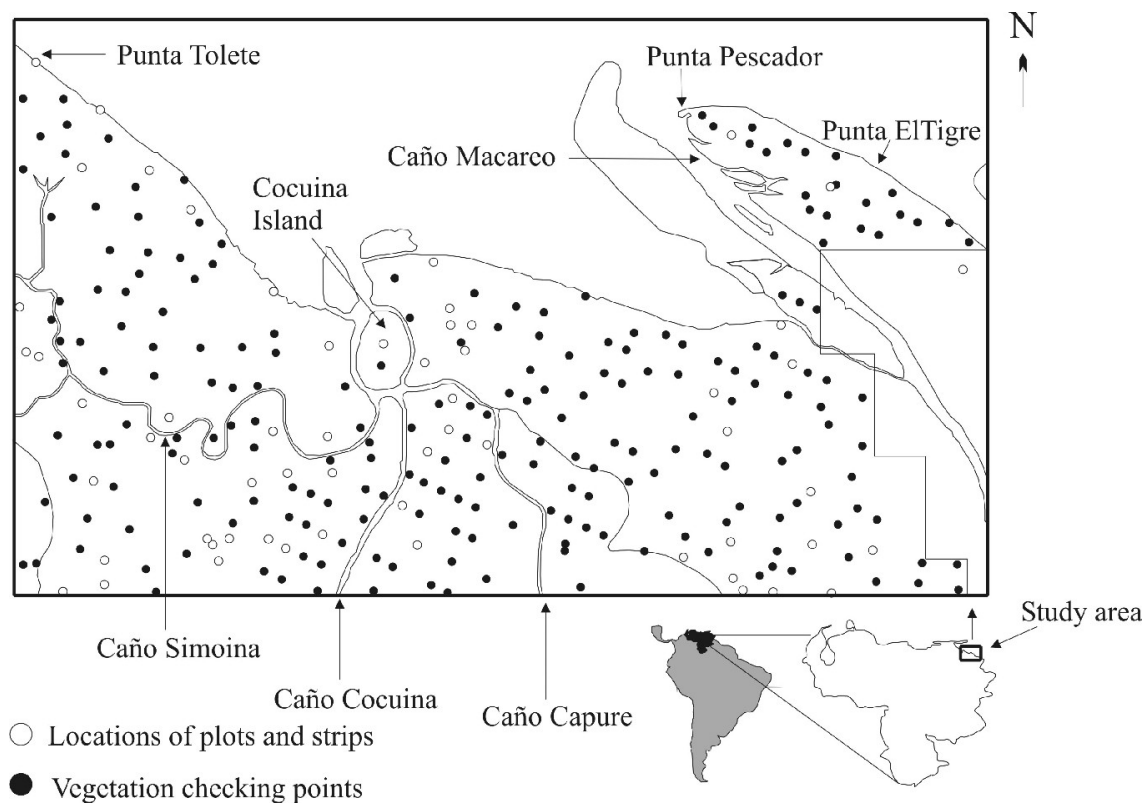

Figure 1: $\quad$ Location of the study area and sampling sites.

The arrangement of vegetation formations is shown in figure 2. Mangroves (MG) of Rhizophora spp. and Avicennia nitida conform gallery/coastal forests along riversides and coasts, covering 20,696 ha $(36.8 \%$ of the studied area). Swamp forests (SF) of Pterocarpus officinalis and Symphona globulifera grow behind the mangrove belts first forming ecotonal areas and then developing landwards. They cover 34,477 ha $(36.8 \%)$. Shrubland $(\mathrm{SH})$ are very scarce (3,070 ha, 3.27\%) and occupy back-mangrove, depresional positions. Meadows (MD) dominated by cyperaceace and ferns occupy 30,752 ha (32.8\%), and palm forests of Mauritia flexuosa (MO), covering 4,827 ha $(8.41 \%)$, are located in the innermost positions $[5,12]$.

\section{Materials and methods}

227 soil sampling sites locations, fig.1, were selected from a vegetation map [5] of the study area (1:400,000). Sampling points were distributed regularly through the area, approaching one sampling site for $4 \mathrm{~km}^{2}$. The number of samples was weighed against the percentage area covered by each vegetation formation. 


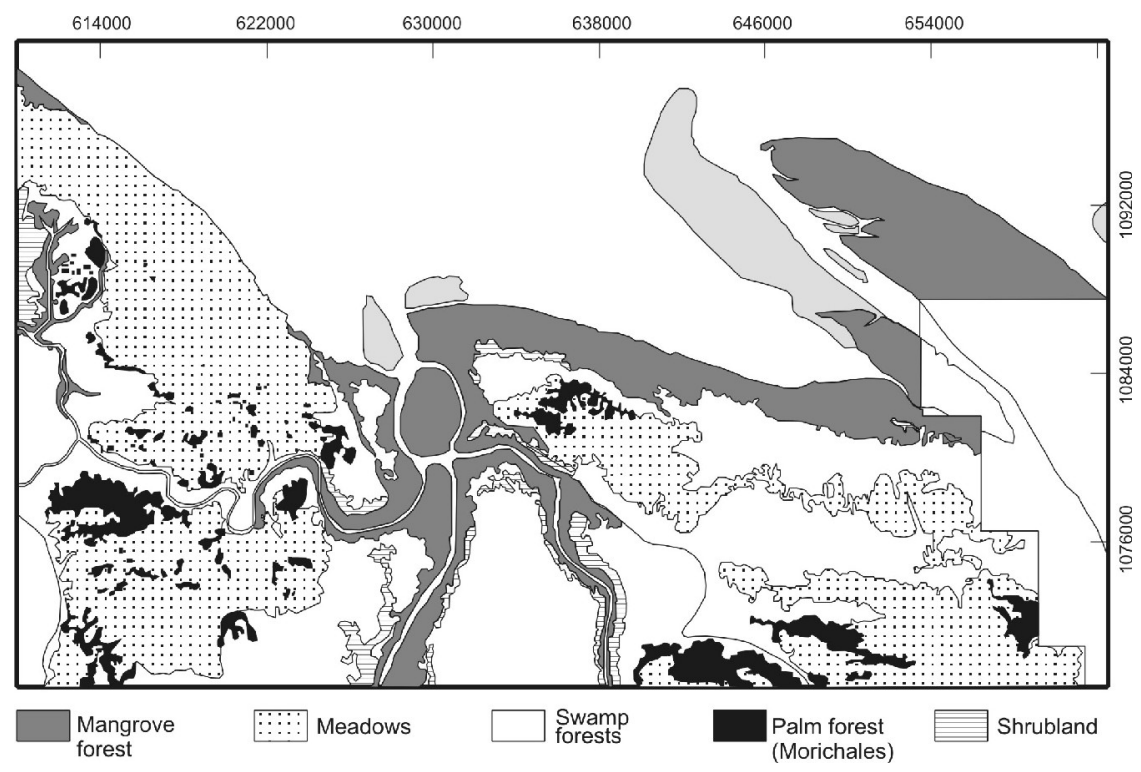

Figure 2: $\quad$ Vegetation formations in the study area.

Soil organic (surface) and mineral (bottom) samples were collected at each sampling point using Edelman and Russian corers. Field observations on local topography, drainage, slope, thickness of the organic layer, and flood water depth were recorded. Soil samples were analyzed for salinity, $\mathrm{pH}$, chlorides $(\mathrm{Cl})$, exchangeable bases: calcium (exCa), magnesium (exMg), potassium (exK), sodium (exNa), and aluminium (exAl), exchangeable hydrogen (exH), exchangeable acidity (exAc), and carbonates $\left(\mathrm{CO}_{3}{ }^{2-}\right)$, following the standard methods of the USDA [11]. Carbonates could not be fulfilled on samples with very high organic content. Organic carbon (OC) analysis was performed with an improved chromic acid digestion and colorimetrically determined [8]. Cation exchange capacity (CEC) at the soil $\mathrm{pH}$ was estimated as the sum of cations extracted including $\mathrm{Al}$ and $\mathrm{H}$ because of $\mathrm{pH}<7$. Base saturation $(\mathrm{BS} \%)$ was calculated as the ratio between exchangeable $\mathrm{Ca}, \mathrm{Mg}, \mathrm{Na}, \mathrm{K}$ and $\mathrm{CEC}$.

Principal Component Analysis (PCA) was performed on a log transformed correlation matrix [4]. The obtained PCA were rotated using Varimax with Kaiser normalization to improve interpretation of results. Statistical treatment was performed by using SPSS v.11.5 package.

\section{Results}

Table 1 shows the averages and standard deviations of each variable of surface and bottom soils arranged by vegetation unit for comparison purposes. All variables showed high variation coefficients (standard deviation / mean) within the same vegetation formations, indicating an elevated spatial heterogeneity. 


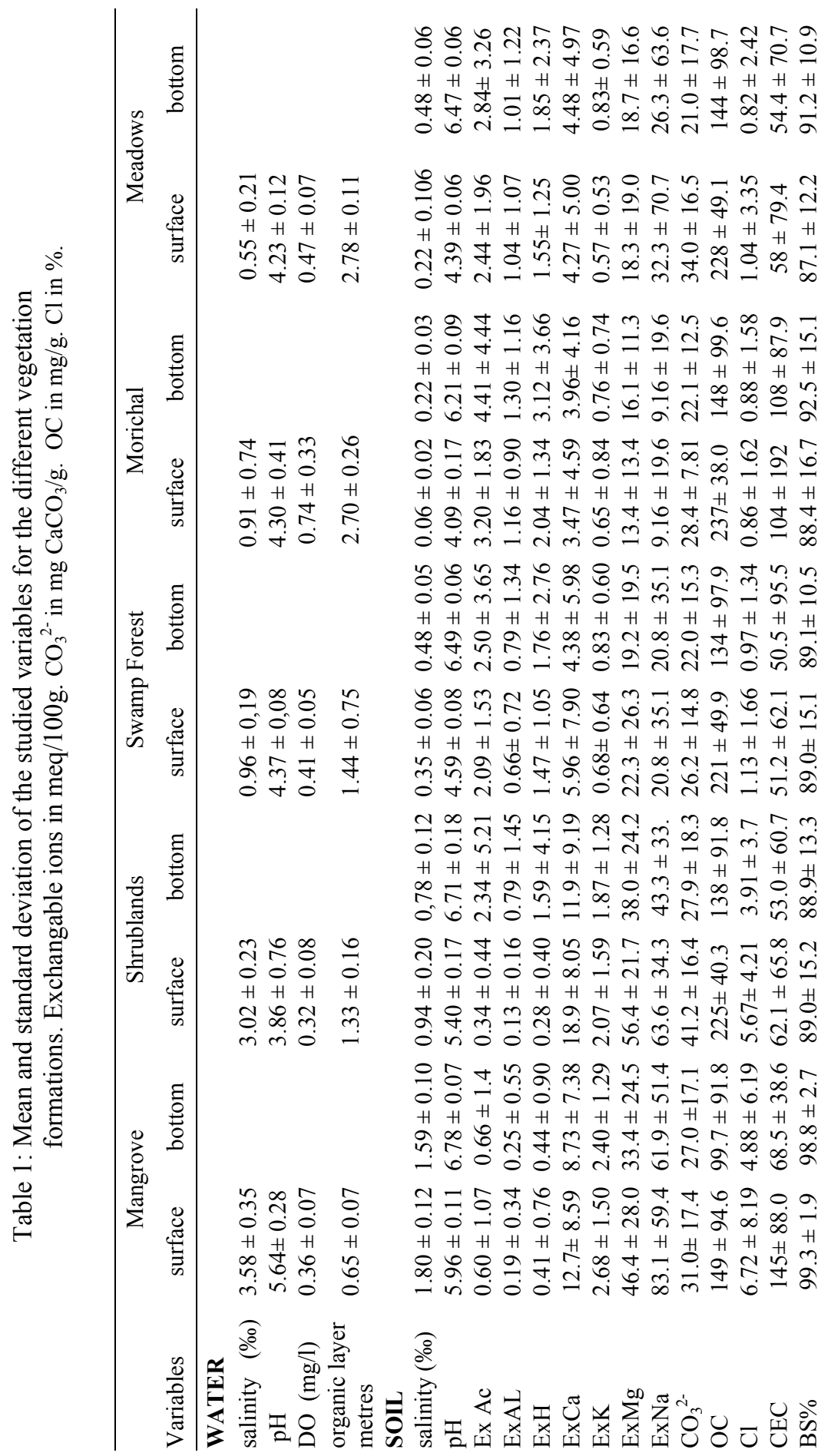


Typical soil profiles consisted of an underlying mineral stratum and a surface peaty organic layer varying from $<1 \mathrm{~m}$ in $\mathrm{MG}$ to $>2 \mathrm{~m}$ in MD and MO. Organic carbon content did not differ significantly among soils from different vegetation units, except for MG soils showing lower concentrations. Surface soil $\mathrm{pH}$ values were increasingly acidic from the coast/riverbanks to the land, while bottom values were less variable and ranged from slightly acidic to neutral. Surface and bottom soil exAc and exH increased strongly and soil salinity declined abruptly, following the same direction. Carbonate concentrations showed little variation among different soils, being the surface values slightly higher than the bottom ones. Alkaline bases $\left(\sum \mathrm{Na}+\mathrm{K}\right)$ prevailed on a earth-alkaline bases $\sum(\mathrm{Ca}+\mathrm{Mg})$ except for the bottom soils of MG and SH. Highest average CEC were found in surface soils of MG. Bottom CEC average values of $\mathrm{MG}, \mathrm{SH}, \mathrm{SF}$ and $\mathrm{MD}$ showed little differences among them. Surface soil BS\% values were high and decreased slightly landward, bottom soils showed little differences.

A Principal Component Analysis (PCA) was applied to log-transformed values of exAc, exH, exCa, exK, exMg, exNa, exK, $\mathrm{Cl}, \mathrm{CEC}, \mathrm{OC}$ and $\mathrm{BS} \%$. PCA is a useful tool to reduce data set dimensionality, and to identify new meaningful underlying variables resulting from the combination of the single ones. PCA extracted two main components which explained $71.8 \%$ of the total variance, $38.1 \%$ and $37.7 \%$ respectively. Table 2 shows the factor loadings of the log-transformed variables and each component. The first component was mainly determined by the CEC with high positive values for concentration of exCa, exNa, exMg and $\mathrm{Cl}$. The second component was mainly related to the soil acidity, with high positive values for exAl, and exH and negative values for $\mathrm{BS} \%$.

Table 2: $\quad$ Varimax rotated factor loadings.

\begin{tabular}{|l|c|c|}
\hline & Component 1 & Component 2 \\
\hline Ex-Acidity & $-0,232$ & 0,913 \\
\hline Ex-Aluminium & $-0,305$ & 0,807 \\
\hline Ex-Hydrogen & $-0,156$ & 0,903 \\
\hline Ex-Calcium & 0,868 & $-0,060$ \\
\hline Ex-Potassium & 0,527 & $-0,590$ \\
\hline Ex-Magnesium & 0,895 & $-0,076$ \\
\hline Ex-Sodium & 0,829 & $-0,300$ \\
\hline Organic Carbon & 0,291 & 0,610 \\
\hline Ex-Chloride & 0,589 & $-0,258$ \\
\hline Cation Exchange Capacity & 0,918 & $-0,100$ \\
\hline \% Base Saturation & 0,471 & $-0,719$ \\
\hline
\end{tabular}


Mangrove

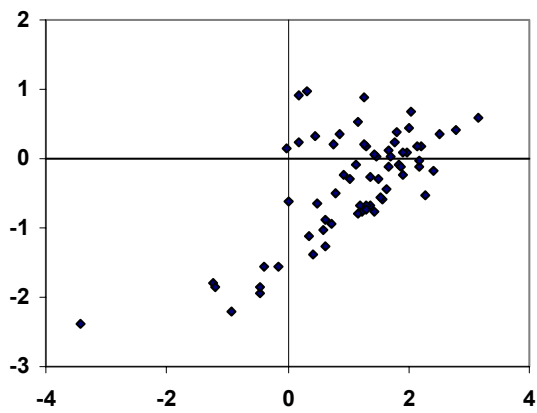

Meadows

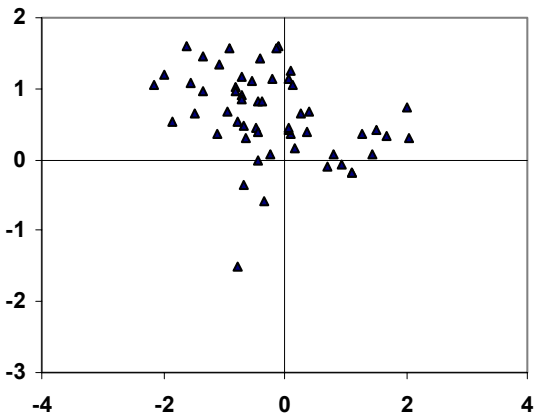

Forest

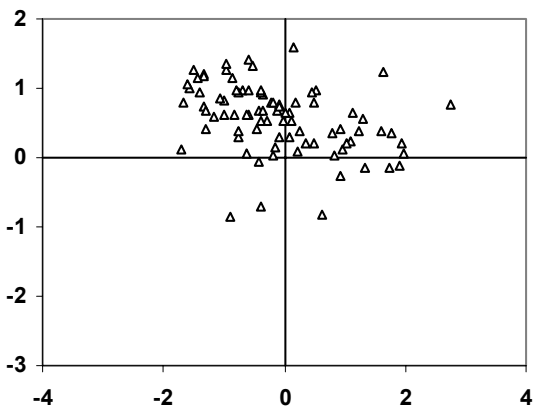

Shrubs and Morichal

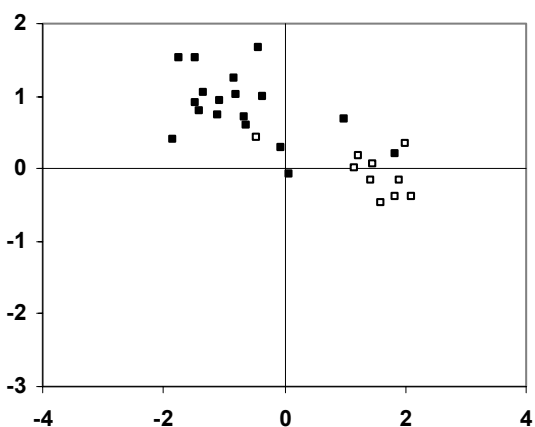

Figure 3: Values of the two first components for surface soil samples grouped by vegetation. PC1: x-axis; PC2: y-axis. Shrubs open squares; Morichal black squares.

The relative position of sampling points with respect to the two principal components provided useful information about the soil-vegetation relationships. To better discriminate the results, surface samples are presented separately for each vegetation formation, fig 3. Most MG samples appeared located in the right side of PC1, but spreading along PC2. SF and MD samples location showed little differences in their position. In both cases most samples were discriminated by PC2 and were situated in the upper part of the graph. Though they spreaded along PC1 with a similar number of samples located both to the right and to the left of the component. Almost all MO samples were situated in the upper left sector, while SH samples appeared to the right of $\mathrm{PC} 1$ both above and below PC2. 


\section{Discussion}

The variation trend of most soil variables suggested that a gradient of edaphic conditions existed from the coast/river margin towards the inner plains. These changes roughly matched variations in vegetation along this same gradient, where successive replacement of plant communities occurred, fig. 2. Contrasting edaphic environments were located at each end of this gradient. The river /coast extreme was exposed to tides and floodwater, covering the neighbourghing surface soils with saline and brackish water twice a day, contributing in this way $\mathrm{Cl}$ and base cations $\mathrm{K}, \mathrm{Ca}, \mathrm{Mg}, \mathrm{Na}$ to the soils. This was reflected by the higher values of these variables close to the water bodies and their decrease landward.

At the landward end of the gradient, peaty, acidic soils prevailed showing acidic $\mathrm{pH}$ values $(<5)$ and the highest exAl, exH and exAc concentrations. Marine or brackish water did not reach these areas, which were dominated by freshwater mainly from pluvial and phreatic origin. It is known that $\mathrm{pH}$ ranges providing optimum growing conditions are between 5.5-8.0 for mineral soils and 4.5-6.0 for organic soils. Below 4.5, soil acidity is known to constrain fertility, promoting toxicity of $\mathrm{H}, \mathrm{Al}$ and $\mathrm{Mn}$ [2,] and deficiencies of $\mathrm{Ca}, \mathrm{Mg}$ and oligoelements [7]. Meadows, especially those located far away from the coast, showed the thickest layers of not decomposed, fibrous ligno-cellulosic debris and lower $\mathrm{pH}$ values, which probably resulted from the degradation of higher plant debris loosing hydrogen bounds through decay processes. Though in some places, MD and SF soil pH values $(22.3 \%)$ were extremely acidic $(<4)$ and may not be explained by organic acids production. This suggested the existence of sulphuric acid generated by pyrite oxidation in the study area. Extense areas of unripe sulphitic soils are known to be concentrated in the Orinoco's Delta [6], where one extremely severe episode of acidification by pyrite oxidation took already place.

CEC measures the ability of soil to retain cation nutrients, $\mathrm{Ca}^{2+}, \mathrm{Mg}^{2+}$ and $\mathrm{K}^{+}$. These elements are usually bound to the negatively charged surfaces of clay and humus particles. As plants absorb these cations, their roots release hydrogen ions $(\mathrm{H}+)$, increasing the environmental acidity. The obtained CEC values fairly surpassed those of fertile soils $(>20 \mathrm{meq} / 100 \mathrm{~g})$ in most samples. This may be explained by the predominance of colloidal organic material and of silt and clays with a great exchange surface in these environments, warranting high CEC along the edaphic gradient. $\mathrm{BS} \%$ showed that the relative proportion of the exchangeable bases $(\mathrm{Ca}, \mathrm{Mg}, \mathrm{Na}, \mathrm{K})$ to the total $\mathrm{CEC}$ was high too $(>60 \%)$, indicating that $\mathrm{CEC}$ was basically determined by those cations, while the acidifying elements $\mathrm{H}^{+}$and $\mathrm{Al}^{3+}$ occupied a low proportion of the soil exchange surfaces.

Based on the foregoing explanations, it is straightforward that $\mathrm{PC} 1$ relates to the content of salts and bases and PC2 with the input of acids to the surface soils. That is, each PC reflects the characteristics of one end of the edaphic gradient. This suggests that the spatial arrangement of vegetation formations and plant communities replacement ( $\beta$ diversity) were influenced by this soil salinity/bases-acidity gradient along the water-land axis. MG and $\mathrm{SH}$ 
concentrated firstly on saline, fairly neutral soils with high CEC. Hence many MG soils were acidic (spreading along PC2). The presence of tidal vegetation like mangroves, water logging and anaerobic conditions is essential for pyrite accumulation, since it favours the active formation of $\mathrm{H}_{2} \mathrm{~S}$ by a permanent supply of sulphates and organic matter for sulphate reduction [13]. On the other hand, mangrove soils are known to accumulate decaying organic matter and phenolic compounds, contributing $\mathrm{H}^{+}$to the edaphic environment. Thus, the discrimination of MG by the two PC reflects probably different environmental situations among them, depending on the combination of tidal flushing/water logging, which in turn depends on their position along the shoreline/ riverbanks or back swamps.

According to $\mathrm{PC} 2$, an important group of SF and MD grew well on acidic, organic soils. In some cases $\mathrm{Al}^{3+}$ was present as well. SF seemed to develop under less extreme conditions. Another group of SF and MD soils were located to the left of PC2, indicating their preference for more neutral soils and certain tolerance to saline conditions. In fact, many SF and MD were relatively close to rivers or the sea, or occupy ecotonal positions behind mangroves, their soils being ocasionaly or periodically covered with flood or tidal water. MO soils showed a clear discrimination by both PC and were located, with one exception, in the upper left sector, suggesting strong affinity to peaty, acidic soils and low salt tolerance.

The results obtained show clearly that the soil-vegetation relationships in the study area depend on complex variables, namely acidity and CEC. Changes in magnitude or range of any of the factors involved in these relations will have a likely impact on vegetation. Environmental management associated with oil resources activities should take into account the complexity of the system and avoid decision based on single characteristics or simplified situations.

\section{References}

[1] Aprioku, I.M., Oil-spill disasters and the rural hazardscape of Eastern Nigeria. Geoforum, 34(1), pp. 99-112, 2003

[2] Barceló, J. \& Poschenrieder, Ch., Fast root growth responses, root exudates, and internal detoxification as clues to the mechanisms of aluminium toxicity and resistance: a review. Environmental and Experimental Botany. 48 (1), pp. 75 - 92, 2002.

[3] Betancourt, N., www.monografiass.com

[4] Cuadras, C., Métodos de Análisis Multivariante, Eunibar: Barcelona, 1981.

[5] Geohidra Consultores C.A., Estudio de Línea Base Ambiental del Bloque Punta Pescador (Vol 1-7). Unpublished Technical Report for AMOCO. Caracas, Venezuela, 1998.

[6] Dent, D.L. \& Pons, L.J., A world perspective on acid sulfate soils. Geoderma, 67, pp. 263-276, 1995. 
[7] Golez, N. \& Kyuma, K., Influence of pyrite oxidation and soil acidification on some essential nutrient elements. Aquaculture Engineering, 16 (1-2), pp. 107-124, 1997.

[8] Heanes, D.L., Determination of total organic-C in soils by an improved chromic acid digestion and spectroscopic procedure. Commun. Soil Sci. Plant Anal., 15, pp. 1191-1213, 1984.

[9] Salter, E. \& Ford, J., Holistic Environmental Assessment and Offshore Oil Field Exploration and Production. Marine Pollution Bulletin, 42(1), pp. 45-58, 2001.

[10] Tolosa, I., de Mora, S., Sheikholeslami, M. R., Villeneuve, J.P., Bartocci, J. \& Cattini, C., Aliphatic and aromatic hydrocarbons in coastal Caspian Sea sediments. Marine Pollution Bulletin, 48 (1-2), pp. 44-60, 2004.

[11] USDA Soil Survey Staff, Keys to Soil Taxonomy. U.S.D.A. Soil Conservation Services, U.S. Govt. Printing Ofice. Whashington D.C. $8^{\text {th }}$ ed., 1991.

[12] Vegas Vilarrúbia, T., Ponce, M.E., Gómez, O. \& Mora, L., Wetland vegetation of the lower Orinoco delta plain (Venezuela): a preliminary approach. (submitted)

[13] Wada, H., Seisuwan, B., The process of pyrite formation in mangrove soils. In: Dorst, H. (Ed.), Selected Papers of the Dakar Symposium on Acid Sulphate Soils. Wagening, Netherlands. ILRI. pp. 24-37, 1988.

[14] Warne, A.G., Meade, R. H., White, W. A., Guevara, E. H., Gibeaut, J., Smyth, R. C., Aslan, A., Tremblay, T., Regional controls on geomorphology, hydrology, and ecosystem integrity in the Orinoco Delta, Venezuela. Geomorphology, 44, pp. 273-307, 2002.

[15] Wells P.G., Duce, R. A. \& Huber, M. E., Caring for the Seaaccomplishments, activities and future of the United Nations GESAMP (the Joint Group of Experts on the Scientific Aspects of Marine Environmental Protection). Ocean \& Coastal Management, 41(1), pp. 77-89, 2002.

[16] WWF \& IUCN, Centers of Plant Diversity: a guide and strategy for their conservation, 3 volumes, Cambridge, IUCN Publications, 1994. 